\title{
SKIRTINGŲ SVORIO KATEGORIJŲ BOKSININKŲ REAKCIJOS, RANKŲ JUDESIŲ GREITUMO IR TIKSLUMO LYGINAMOJI ANALIZE்
}

\author{
Vidas Bružas, Algirdas Čepulėnas, Dalia Mickevičienė, Pranas Mockus \\ Lietuvos kūno kultūros akademija, Kaunas, Lietuva
}

Vidas Bružas. Biomedicinos mokslų daktaras. Lietuvos kūno kultūros akademijos Individualių sporto šakų katedros lektorius. Mokslinių tyrimų kryptis — dvikovos šakų sportininkų rengimo technologijos ir jų modeliavimas.

\section{SANTRAUKA}

Tyrimo tikslas - nustatyti ir išanalizuoti skirtingu svorio kategoriju boksininku reakcijos laiko, judesiu greičio ir judesiu tikslumo rodiklius atliekant užduotis dešine ir kaire ranka.

Ištirta 14 skirtingu svorio kategoriju boksininku, kurie buvo suskirstyti i dvi grupes. Pirmoje grupëje buvo lengvojo $(48-60 \mathrm{~kg})$ svorio kategoriju boksininkai $(\mathrm{n}=6)$, antroje — sunkiojo (75-100 kg). Tiriamieji — Lietuvos nacionalinès ir jaunimo bokso rinktiniu kandidatai.

Boksininku reakcijos laiko, judesiu greičio ir judesiu tikslumo rodikliai buvo registruojami žmogaus ranku ir koju judesiu analizatoriumi DPA-1 (patento Nr. 5251, 2005-08-25) pagal Lietuvos kūno kultūros akademijos Žmogaus motorikos laboratorijos aprobuota tyrimo metodika (Zuoziene ir kt., 2005). Buvo registruojamas reakcijos laikas, ranku judesiu greitis, tikslumas. Užduotys atliktos dešine ir kaire ranka.

Lengvojo svorio kategoriju (I gr.) boksininku reakcijos i dirgikli laiko rodikliai atliekant užduoti dešine ranka 263,7 $\pm 41,9$ ms, kaire - 279,9 \pm 67,2 ms. Sunkiojo svorio kategoriju (II gr.) boksininku reagavimo ì dirgikli laikas dešine ranka - 250,6 \pm 27,3 ms, kaire - 243,2 \pm 33,4 ms. Didžiausias rankos judesiu greitis nustatytas II gr. boksininku: dešinès rankos - 216,6 \pm 30,6 cm / s, kairès - 197,3 $\pm 26,4 \mathrm{~cm} / \mathrm{s}$.

Boksininku didžiausiojo judesio greičio rodikliai priklauso nuo užduoties sudètingumo - greita ir tikslu judesí tiriamieji atliko léčiau nei paprasta ir greita. Sunkiojo svorio kategoriju boksininkai yra greitesnès reakcijos, didesnis ju ranku judesiu didžiausiasis greitis ir judesiu tikslumas nei lengvojo svorio kategoriju boksininku, tačiau šis skirtumas mažas.

Raktažodžiai: reakcijos laikas, judesio greitis, judesio tikslumas.

\section{IVADAS}

$\mathrm{B}$ oksininkų varžybinè veikla labai dinamiška, didelè varžybinių situacijų kaita, psichinè itampa, atliekamų smūgių ir gynybos veiksmų ivairovė (Coaching Olympic Style, Boxing, 1995; Hatmaker, Werner, 2004; Санников, Воропаев, 2006). Labai svarbūs boksininkų sportinio parengtumo komponentai — sensomotoriniai gebejjimai (Гаськов, 2000; Кличко, Савчин, 2000) (tai gebėjimai greitai, išradingai ir tiksliai veikti įvairiomis varžybinès kovos situacijomis).
Visais metinio ciklo etapais boksininkų specialusis parengtumas glaudžiai koreliuoja su sensomotorinèmis reakcijomis (Гаськов, 2000). Boksininku technini parengtumą daug lemia psichomotorinè reakcija, judesių greitumas ir suderinamumas, judesių smūgiuojant tikslumas (Valentino et al., 1990; Guidetti et al., 2002; Колесник, Назаренко, 2005). Skirtingu svorio kategorijų boksininkų reakcijos, judesiu greitumo ir tikslumo raiškos ypatumai mažai tirti, todèl šiuo tyrimu pabandyta 


\begin{tabular}{|c|c|c|c|c|}
\hline Boksininkų grupės & Amžius, m. & $\overline{\text { Ügis, }} \mathbf{c m}$ & Kūno svoris, kg & $\begin{array}{l}1 \text { lentelè. Boksininku amžiaus, ūgio ir kūno } \\
\text { svorio rodikliai }\left(\overline{\mathbf{X}}_{ \pm \mathrm{SD}}\right)\end{array}$ \\
\hline I gr., lengvojo svorio kategoriju & $19,3 \pm 6,4$ & $165,5 \pm 10,5$ & $57,2 \pm 9,0$ & \\
\hline II gr., sunkiojo svorio kategoriju & $21,1 \pm 4,2$ & $185,4 \pm 8,9$ & $82,9 \pm 12,9$ & \\
\hline
\end{tabular}

nagrinèti lengvojo ir sunkiojo svorio kategoriju boksininkų reakcijos, judesių greičio ir tikslumo rodiklius.

Tyrimo tikslas - nustatyti skirtingu svorio kategorijų boksininkų reakcijos laiko, judesių greičio ir tikslumo raiškos ypatumus atliekant užduotis dešine ir kaire ranka.

Tiriamieji ir tyrimo metodika. Buvo tiriama 14 skirtingu svorio kategorijų boksininku̧, kurie suskirstyti i dvi grupes (1 lent.). Pirmoje grupèje - lengvojo (48-60 kg) svorio kategorijų boksininkai $(n=6)$, antroje — sunkiojo (75-100 kg; $\mathrm{n}=8$ ). Tiriamieji - Lietuvos nacionalinès ir jaunimo bokso rinktinių kandidatai. Visi boksininkai buvo dešiniarankiai — priekinè ranka — kairè (silpnesnioji), pagrindinè — dešinè (stiprioji). Boksininkų rezultatai buvo palyginami su kontrolinès grupės adekvačiais duomenimis.

Kontrolinę grupę sudarè 50 kariūnų (Lietuvos karo akademijos studentu), kurie buvo tiriami pagal tą pačią metodiką (Zuozienė ir kt., 2005).

Tyrimas atliktas Lietuvos kūno kultūros akademijos Žmogaus motorikos laboratorijoje. Boksininkų reakcijos laiko, judesių greičio ir tikslumo rodikliai buvo registruojami žmogaus rankų ir kojų judesių analizatoriumi DPA-1 (patento Nr. 5251, 2005-08-25) pagal aprobuotą tyrimo metodiką (Zuozienè ir kt., 2005).

Tiriamieji atliko po tris skirtingas užduotis dešine ir kaire ranka:

- Reakcijos laikui nustatyti tiriamasis, laikydamas specialią prietaiso rankeną, turèdavo kuo greičiau sureaguoti i̇ duodamą signalą žalią spalvą kompiuterio ekrane. Reakcijos laikas (ms) registruojamas užduotị atliekant dešine ir kaire ranka.

- Judesio greičiui nustatyti tiriamasis, laikydamas specialią prietaiso rankeną, turèdavo kuo greičiau sureaguoti i duodamą signalą ir visiškai ištiesti ranką. Buvo registruojamas dešinès ir kairès rankos judesio greitis $(\mathrm{cm} / \mathrm{s})$.

- Judesių tikslumui nustatyti tiriamasis, laikydamas prietaiso specialią rankeną, turèdavo kuo greičiau sureaguoti i ekrane pasirodanti taikini ir stumti prietaiso rankeną taip, kad simbolio skritulys ekrane kuo greičiau tikslia trajektorija pasiektų taikinio skritulį ir sustotų jame (Zuoziené ir kt., 2007).

Buvo fiksuojamas reakcijos laikas (ms), rankos judesio greitis $(\mathrm{cm} / \mathrm{s})$, judesio atlikimo laikas (ms), rankos judesio trajektorijos atstumas nuo starto iki pataikymo į taikini $(\mathrm{cm})$ atliekant užduoti dešine ir kaire ranka.

Apskaičiuotos tiriamų rodiklių aritmetinio vidurkio $(\bar{X})$ reikšmés, vidutinis standartinis nuokrypis (SD), rezultatu skirtumo tarp grupių patikimumo lygmuo - pagal Studento $t$ kriterijų. Skaičiavimai atlikti naudojant statistini paketą Statistica for Windows.

\section{REZULTATAI}

Sunkiojo svorio kategorijų boksininkų (II gr.) psichomotorinès reakcijos reagavimo į regos dirgiklị laikas dešine ir kaire ranka buvo trumpesnis negu lengvojo svorio (I gr.), nors skirtumas nèra statistiškai patikimas (2 lent.). Atliekant tikslumo užduotị, i̇ dirgikli greičiausiai reagavo I gr. boksininkai, atlikdami užduoti kaire ranka -

\begin{tabular}{|c|c|c|c|c|}
\hline \multirow{3}{*}{ Tiriamų boksininkų grupės } & \multicolumn{4}{|c|}{ Psichomotorinės reakcijos laikas, ms } \\
\hline & \multicolumn{2}{|c|}{ Reakcijos užduotis } & \multicolumn{2}{|c|}{ Tikslumo užduotis } \\
\hline & Dešine ranka & Kaire ranka & Dešine ranka & Kaire ranka \\
\hline I gr., lengvojo svorio kategorijų & $263,7 \pm 41,9$ & $279,9 \pm 67,2$ & $261,2 \pm 49,3$ & $249,8 \pm 55,6$ \\
\hline II gr., sunkiojo svorio kategorijų & $250,6 \pm 27,3$ & $243,2 \pm 33,4$ & $255,4 \pm 45,2$ & $259,5 \pm 53,9$ \\
\hline $\mathrm{t}$ & 0,6 & 1,20 & 0,21 & 0,31 \\
\hline $\mathrm{p}$ & $>0,05$ & $>0,05$ & $>0,05$ & $>0,05$ \\
\hline $\begin{array}{l}\text { Kariūnai } \\
\text { (Zuozienė ir kt., 2005) }\end{array}$ & $265,4 \pm 26,5$ & $275,2 \pm 35,4$ & $271,7 \pm 32,0$ & $278,8 \pm 32,3$ \\
\hline $\begin{array}{l}\text { I gr. — kariūnai } \\
\text { t } \\
\text { p }\end{array}$ & $\begin{array}{l}0,1 \\
>0,05\end{array}$ & $\begin{array}{l}0,17 \\
>0,05\end{array}$ & $\begin{array}{l}0,51 \\
>0,05\end{array}$ & $\begin{array}{l}1,25 \\
>0,05\end{array}$ \\
\hline $\begin{array}{l}\text { II gr. — kariūnai } \\
\text { t } \\
\text { p }\end{array}$ & $\begin{array}{l}1,43 \\
>0,05\end{array}$ & $\begin{array}{l}2,50 \\
<0,025 \\
\end{array}$ & $\begin{array}{l}0,98 \\
>0,05\end{array}$ & $\begin{array}{l}0,98 \\
>0,05 \\
\end{array}$ \\
\hline
\end{tabular}

2 lentelè. Boksininkų psichomotorinès reakcijos laikas atliekant skirtingas užduotis ( $\overline{\mathbf{X}} \pm \mathrm{SD}$ ) 
3 lentelè. Boksininkų rankų judesių greitis atliekant skirtingas užduotis $(\overline{\mathbf{X}} \pm \mathrm{SD})$

\begin{tabular}{|l|l|l|l|l|}
\hline \multirow{2}{*}{ Tiriamų boksininkų grupès } & \multicolumn{4}{|c|}{ Judesių greitis, cm / s } \\
\cline { 2 - 5 } & \multicolumn{2}{|c|}{ Greitumo užduotis } & \multicolumn{2}{c|}{ Tikslumo užduotis } \\
\cline { 2 - 5 } & Dešine ranka & \multicolumn{1}{|c|}{ Kaire ranka } & \multicolumn{1}{c|}{ Dešine ranka } & \multicolumn{1}{|c|}{ Kaire ranka } \\
\hline I gr., lengvojo svorio kategorijų & $199,3 \pm 39,7$ & $189,3 \pm 42,7$ & $142,5 \pm 26,7$ & $134,7 \pm 19,8$ \\
\hline II gr., sunkiojo svorio kategoriju & $216,6 \pm 30,6$ & $197,3 \pm 26,4$ & $170,5 \pm 46,1$ & $157,6 \pm 30,0$ \\
\hline $\mathrm{t}$ & 0,85 & 0,39 & 1,29 & 1,56 \\
\hline $\mathrm{p}$ & $>0,05$ & $>0,05$ & $>0,05$ & $>0,05$ \\
\hline Kariūnai (Zuozienė ir kt., 2005) & $239,6 \pm 29,6$ & $237,5 \pm 43,9$ & $165,9 \pm 30,8$ & $183,9 \pm 48,1$ \\
\hline $\begin{array}{l}\text { I gr. - kariūnai } \\
\text { t }\end{array}$ & 2,41 & 2,60 & 1,99 & 3,37 \\
p & $<0,025$ & $<0,025$ & $>0,05$ & $<0,005$ \\
\hline $\begin{array}{l}\text { II gr. - kariūnai } \\
\text { t } \\
\text { p }\end{array}$ & 1,98 & $\begin{array}{l}3,58 \\
<0,001\end{array}$ & $\begin{array}{l}0,06 \\
>0,05\end{array}$ & $\begin{array}{l}2,09 \\
<0,05\end{array}$ \\
\hline
\end{tabular}

4 lentelè. Boksininkų rankụ judesių tikslumo rodikliai $(\overline{\mathbf{X}} \pm \mathrm{SD})$

\begin{tabular}{|l|l|l|l|l|}
\hline \multirow{2}{*}{ Tiriamų boksininkų grupės } & \multicolumn{2}{c|}{$\begin{array}{c}\text { Judesio atlikimo nuo starto iki } \\
\text { taikinio laikas, ms }\end{array}$} & \multicolumn{2}{c|}{$\begin{array}{c}\text { Atstumas nuo starto iki } \\
\text { taikinio, cm }\end{array}$} \\
\cline { 2 - 5 } & \multicolumn{1}{|c|}{ Dešine ranka } & \multicolumn{1}{c|}{ Kaire ranka } & Dešine ranka & Kaire ranka \\
\hline I gr., lengvojo svorio kategorijų & $1153,2 \pm 212,8$ & $1130,7 \pm 296,4$ & $31,7 \pm 2,3$ & $30,2 \pm 1,2$ \\
\hline $\begin{array}{l}\text { II gr., sunkiojo svorio katego- } \\
\text { rijų }\end{array}$ & $1080,7 \pm 121,1$ & $1091,9 \pm 130,1$ & $31,7 \pm 1,3$ & $31,1 \pm 1,7$ \\
\hline t & 0,73 & 0,29 & 0,04 & 1,02 \\
\hline p & $>0,05$ & $>0,05$ & $>0,05$ & $>0,05$ \\
\hline
\end{tabular}

1 pav. Lengvojo svorio kategorijų boksininkų individualūs reakcijos laiko rodikliai atliekant reakcijos užduotị

2 pav. Sunkiojo svorio kategorijų boksininkụ individualūs reakcijos laiko rodikliai atliekant reakcijos užduotị
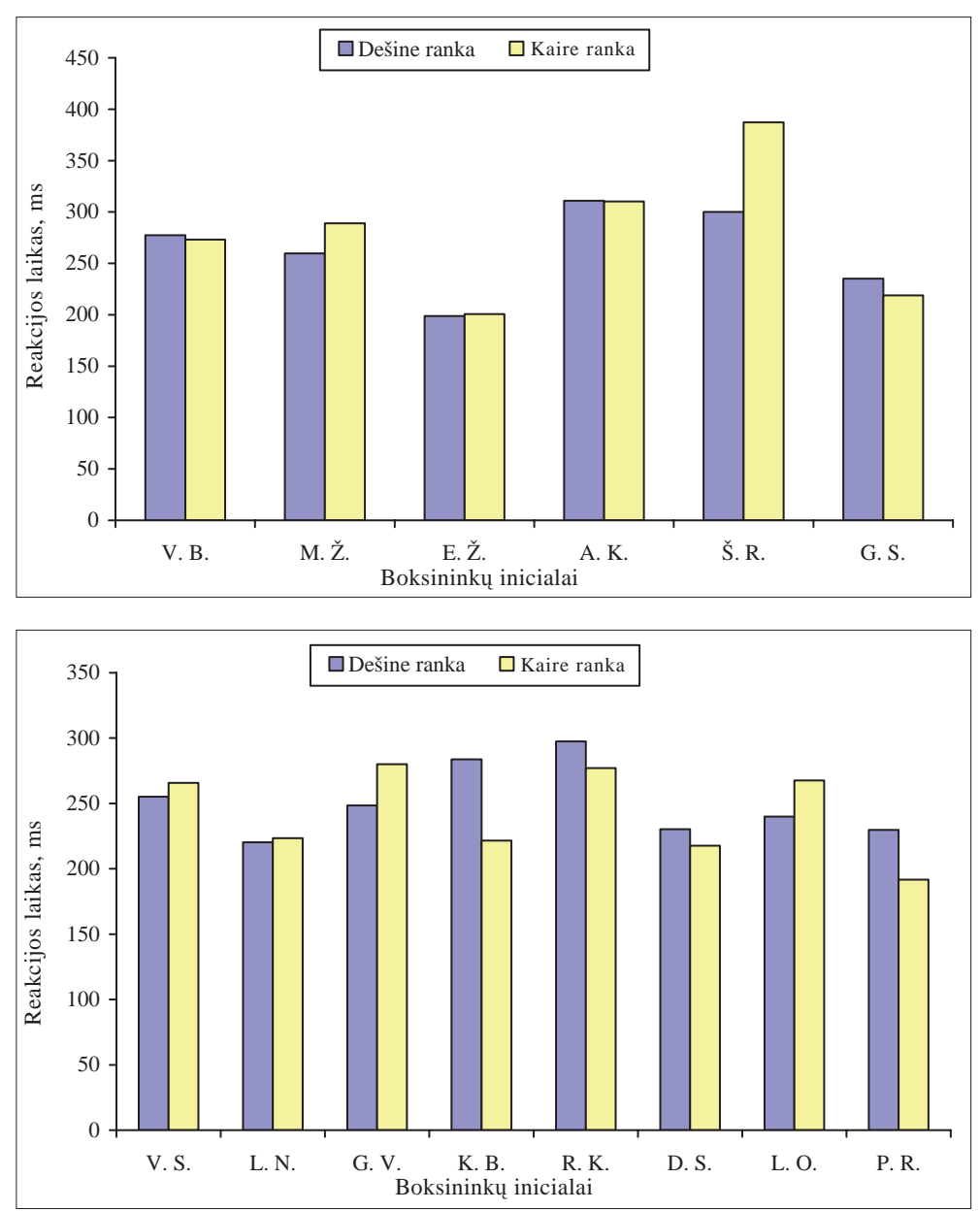

249,8 \pm 55,6 ms. II gr. boksininkai šios užduoties metu greičiau i dirgikli reagavo dešine ranka 255,4 \pm 45,2 ms (2 lent.).

Didžiausias rankos judesnio greitis nustatytas tarp II gr. boksininkų: dešine ranka 216,6 \pm 30,6 cm / s, kaire - 197,3 $\pm 26,4 \mathrm{~cm} / \mathrm{s}$.

Atlikdami tiek greitumo, tiek tikslumo užduotis, abiejų grupių boksininkai didesnị rankos judesio greiti pasiekė dešine ranka (3 lent.).
I gr. boksininkų rankos judesio greitis atliekant greitumo ir tikslumo užduotis buvo nedaug mažesnis ( $\mathrm{p}>0,05)$ už II gr. boksininkų (3 lent.). 

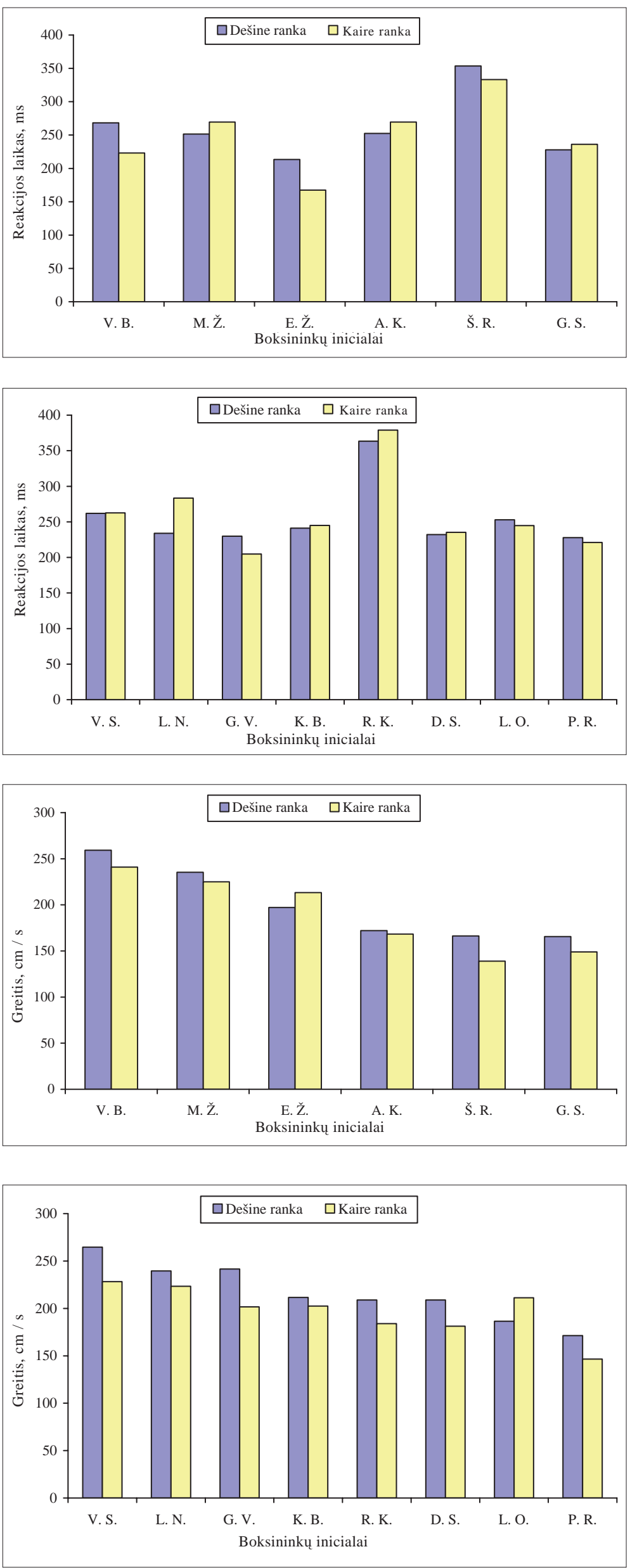

3 pav. Lengvojo svorio kategorijų boksininkų individualūs reakcijos laiko rodikliai atliekant tikslumo užduotị

4 pav. Sunkiojo svorio kategorijų boksininkų individualūs reakcijos laiko rodikliai atliekant tikslumo užduoti

5 pav. Lengvojo svorio kategorijų boksininkų individualūs rankų judesių greičio rodikliai atliekant greitumo užduotị

6 pav. Sunkiojo svorio kategorijų boksininkų individualūs rankų judesių greičio rodikliai atliekant greitumo užduotị 
II gr. boksininkai tikslumo judesi (4 lent.) dešine ranka atliko per 1080,7 $\pm 121,1 \mathrm{~ms}$, kaire - per 1091,9 \pm 130,1 ms (buvo fiksuojamas laikas nuo starto iki pataikymo i taikini), I gr. - atitinkamai per $1153,2 \pm 212,8 \mathrm{~ms}$ ir $1130,7 \pm 296,4 \mathrm{~ms}$ ( $p>0,05)$. Pirmos ir antros grupès boksininku dešinès ir kairès rankos judesio tikslumo rodikliai (rankos trajektorijos atstumas nuo starto iki taikinio) buvo beveik vienodi ( $p>0,05)$ : nuo 30,2 $\pm 1,2$ iki 31,7 $\pm 1,3 \mathrm{~cm}$ (4 lent.).

Analizuojant didelio meistriškumo boksininku sportini parengtumą svarbu žinoti psichomotoriniu gebejjimų individualias reikšmes, kad būtų galima tikslingai koreguoti jų lavinimą. Tiriamų boksininkų individualios psichomotorinės reakcijos ranku judesių greičio reikšmės pateiktos $1-6$ paveiksluose.

\section{REZULTATŲ APTARIMAS}

Boksininkams labai svarbi regos sensorinė sistema, nuo kurios priklauso regos lauko dydis, vaizdinès informacijos suvokimas, gebèjimas pastebėti svarbiausius varžovo veiksmus (Санников, Воропаев, 2006). Boksininkams kovojant ringe per varžybas, kai kuriais kovos momentais net keliolika milisekundžiu greitesnis ar lètesnis reagavimas į varžovo veiksmus gali būti labai reikšmingas.

Tyrimo duomenys parodè, kad individualūs psichomotorinès reakcijos rodikliai tiek lengvojo, tiek sunkiojo svorio kategorijų boksininku grupèse skirtingi (1-4 pav.). Lengvojo svorio kategorijų (I gr.) boksininkų individualūs reakcijos ị regos dirgikli rodikliai atliekant užduoti dešine ranka — nuo 198,7 iki 311 ms, kaire — nuo 200,6 iki 387,8 ms (1 pav.). Sunkiojo svorio kategorijų boksininku (II gr.) reakcijos laiko trukmè dešine ranka - nuo 220,2 iki 297,2 ms, kaire - nuo 191,7 iki 280,6 ms (2 pav.). Boksininkų psichomotorinès reakcijos reikšmės iš esmès nesiskyrè $(p>0,05)$ nuo kontrolinės grupès kariūnų vidutinių reikšmių (2 lent.). Tik sunkiojo svorio kategorijų boksininku psichomotorinès reakcijos laikas reaguojant kaire ranka buvo daug trumpesnis negu kariūnu ( $<<0,025)$. Boksininkai pratybų ir varžybinės kovos metu priekine ranka (kaire, jeigu boksininkas dešiniarankis, ir dešine - jeigu kairiarankis) atlieka daug greitu̧, jëgos nereikalaujančių veiksmų ir parengiamuju smūgių. Priekine ranka boksininkas nukreipia varžovo dèmesị nuo rengiamos pagrindinès atakos ar smūgio stipresniaja ranka. Dèl tokio ilgalaikio treniravimosi judesiai priekine ranka pasidaro greitesni negu stipresniaja. Tai galëjo lemti trumpesni didelio meistriškumo sunkiojo svorio kategorijų boksininkų reakcijos laiką šio tyrimo metu. Ko gero, žmogaus psichomotorinius ypatumus lemia paveldimumo ir aplinkos (ugdymo, lavinimo, mokymo) veiksniai arba paveldimumo ir aplinkos veiksnių sąveika (Yan et al., 2000). Analizuojant atskirus psichomotorinès reakcijos komponentus, svarbu žinoti ir judesio struktūrą (Muckus, 2003).

Lengvojo svorio kategorijų boksininkų individualūs reakcijos laiko rodikliai atliekant tikslumo užduoti dešine ranka - nuo 213,3 iki 353,6 ms, kaire — nuo 167,4 iki 333,3 ms (3 pav.). Sunkiojo svorio kategorijų boksininkų individualūs reakcijos laiko rodikliai atliekant tikslumo užduoti dešine ranka - nuo 229,9 iki 363,4 ms, kaire - nuo 204,7 iki 378,9 ms (4 pav.).

Psichomotorinè reakcija yra sudètingas sąlyginis motorinis refleksas, kurị lemia didžiujuc pusrutulių funkcinès būklès pakitimas, todèl iš psichomotorinès reakcijos laiko galima šiek tiek spręsti apie tiriamų sportininkų antrinės nervų sistemos funkcinę būklę (Skernevičius ir kt., 2004). Psichomotorinės reakcijos laiką sudaro paprastosios reakcijos laikas, situacijos suvokimo laikas, judesio atlikimo laikas (Muckus, 2001). Psichomotorinès reakcijos laikas priklauso nuo judejjimo užduoties sudètingumo. Sportininkams ypač svarbus psichomotorinès reakcijos laikas, parodantis reakciją $i$ nuolat besikeičiančią aplinką, artimą varžybinei veiklai (Muckus, 2003).

Lengvojo svorio kategorijų boksininkų (I gr.) rankos judesių didžiausiojo greičio rodikliai dešine ranka - nuo 166,3 iki 259,3 cm / s, kaire — nuo 139,0 iki 241,0 cm / s (5 pav.). Sunkiojo svorio boksininkų (II gr.) individualūs rankos judesio didžiausiojo greičio rodikliai dešine ranka - nuo 171,3 iki 264,7 cm / s, kaire - nuo 146,5 iki $228 \mathrm{~cm} / \mathrm{s}$ (6 pav.).

Greitus rankos judesius gali atlikti tiek lengvojo, tiek sunkiojo svorio kategorijų boksininkai.

Greitą ir tikslų judesi (3 lent.) abiejų grupių boksininkai atliko lèčiau nei paprastą greitą. Kuo sudettingesnis judesys, tuo daugiau laiko reikia galvos smegenyse sukurti judesio planą ir judesių programą bei ją realizuoti (Latash, 1998). Ši teigini patvirtino ir atlikto tyrimo rezultatai. Boksininkų kai kurios rankų judesių greičio rodiklių vidutinès reikšmės buvo prastesnès negu kariūnų (3 lent.). Boksininkai per pratybas turètų daugiau lavinti greitumo gebėjimus.

Atlikdami tikslumo užduoti, pagal judesio atlikimo trukmę nuo starto iki pataikymo į taikinị sun- 
kiojo svorio kategorijų (II gr.) boksininkai buvo šiek tiek tikslesni negu lengvojo (I gr.) (4 lent.). Sudètingoje boksininkų varžybinèje veikloje svarbu reakcijos, judesių greitumo, judesių tikslumo gebejjimai ir jų tinkamas realizavimas įvairiomis kovos situacijomis (Гаськов, 2000; Кличко, Савчин, 2000). Tyrimo rezultatai parodè, kad panašaus sportinio meistriškumo ir panašių svorio kategorijų boksininkų individualūs reakcijos, ran$\mathrm{ku}$ judesių greitumo bei tikslumo rodikliai skiriasi ir šiuos skirtumus gali lemti tiek individualūs genetiniai gebejimai, tiek treniravimo technologijos ypatumai. Deja, literatūroje neradome duomenu apie boksininku psichomotorinius ypatumus, nustatytus taikant mūsų naudotus tyrimo metodus ir kuriuos galètume palyginti su mūsų tirtų boksininkų duomenimis.

\section{IŠVADOS}

1. Statistiškai reikšmingo skirtumo tarp lengvojo ir sunkiojo svorio kategorijų boksininkų reakcijos, ranku judesių greičio ir tikslumo vidutiniu reikšmių nenustatyta. Sunkiojo svorio kategorijų boksininkų reakcijos, didžiausiojo rankų judesių greičio ir judesių tikslumo vidutinès reikšmės buvo šiek tiek geresnès negu lengvojo svorio kategoriju boksininku, tačiau šie skirtumai maži.

2. Panašaus sportinio meistriškumo boksininku individualūs psichomotorinès reakcijos, ranku judesiu greitumo ir tikslumo rodikliai skiriasi, todèl i šiu rodiklių reikšmes tikslinga atsižvelgti koreguojant individualuji boksininku rengimą.

\section{LITERATŪRA}

Coaching Olympic Style Boxing. (1995). Publisher I. L. Cooper. United States Amateur Boxing, Inc.

Guidetti, L., Musulin, A., Baldari, C. (2002). Physiological factors in middleweight boxing performance. The Journal of Sports Medicine and Physical Fitness, 42 (3), 309-314.

Hatmaker, M., Werner, D. (2004). Boxing Mastery: Advanced Technique, Tactics and Strategies from the Sweet Science. San Diego, California: Tracks Publishing.

Latash, M. L. (1998). Neurophysiological Basis of Movement. Champaign, IL: Human Kinetics.

Muckus, K. (2003). Psichomotorinės reakcijos ir jos komponentų priklausomybè nuo judèjimo užduoties sunkumo. Ugdymas. Kūno kultūra. Sportas, 4 (49), 35-40.

Muckus, K. (2001). Žmogaus fiziniu gebejjimu biomechanika: mokomoji priemonè. Kaunas: LKKA.

Skernevičius, J., Raslanas, A., Dadeliene, R. (2004). Sporto mokslo tyrimu metodologija. Vilnius: LSIC.

Yan, J. H., Thomas, R. T., Stelmach, G. E., Thomas, K. T. (2000). Developmental features of rapid aiming arm movements across the lifespan. Journal of Motor Behavior, 32, 2, 121-140.

Valentino, B., Esposito, L. C., Fabozzi, A. (1990). Elec- tromyographic activity of a muscular group in movements specific to boxing. The Journal of Sports Medicine and Physical Fitness, 29, 677-693.

Zuozienė, I. J., Skurvydas, A., Mickevičienė, D. ir kt. (2007). Judesių reakcijos laiko ir greičio analizè. Sporto mokslas, 1 (47), 40-47.

Zuozienè, I. J., Skurvydas, A., Mickevičienè, D. ir kt. (2005). Kariūnu rankų psichomotorinių savybių tyrimas naudojant DPA-1 analizatorių. Ugdymas. Kūno kultūra. Sportas, 4 (58), 67-73.

Гаськов, А. В. (2000). Факторная структура тренировочных средств квалифицированных боксёров на разных этапах подгоовки. Теория и практика физической культуры, 10, 48-51.

Кличко, В., Савчин, М. (2000). Система тестов для оценки специальной подготовленности боксёров высокой квалификации. Наука в олимпийском спорте, 2, 23-30.

Колесник, И. С., Назаренко, Л. В. (2005). Новые подходы к развитию ловкости боксёров. Теория и практика физической культуры, 3, 59-61.

Санников, В. А., Воропаев, В. В. (2006). Теоретические и методические основы подготовки боксёра. Москва: Физическая культура. 


\title{
COMPARATIVE ANALYSIS OF REACTION, HAND MOVEMENTS, SPEED AND ACCURACY OF BOXERS IN DIFFERENT WEIGHT CATEGORIES
}

\author{
Vidas Bružas, Algirdas Čepulėnas, Dalia Mickevičienė, Pranas Mockus \\ Lithuanian Academy of Physical Education, Kaunas, Lithuania
}

\begin{abstract}
The aim of the research was to determine and analyze the indices of reaction time, movement speed and movement accuracy of boxers in different weight categories when they performed the tasks with their right and left hands.

The research participants were 14 boxers of different weight categories who were divided into two groups. The first group included boxers $(n=6)$ of lightweight categories $(48-60 \mathrm{~kg})$, and the second $(\mathrm{n}=8)$ - of heavyweight categories $(75-100 \mathrm{~kg})$. The boxers researched were candidates of Lithuanian national and youth teams.

The parameters of boxers' reaction time, movement speed and movement accuracy were registered applying the analyzer of dynamic parameters of human hand and leg movement DPA-1 (Patent No. 5251, 2005-08-25) according to the approbated research methods at the Laboratory of Human Motorics, the Lithuanian Academy of Physical Education (Zuoziene et al., 2005). We registered reaction time, speed of hand movements and accuracy of hand movements. The tasks were performed with the right and the left hands. The indices of reaction time of boxers in lightweight categories (Group 1) performing the task with their right hand were $263.7 \pm 41.9 \mathrm{~ms}$, and with their left hand $-279.9 \pm 67.2 \mathrm{~ms}$. In heavyweight categories (Group 2) the boxers' reaction time reacting to the stimulus with their right hand was $250.6 \pm 27.3 \mathrm{~ms}$, and with their left hand $-243.2 \pm 33.4 \mathrm{~ms}$. The greatest hand movement speed was reached by the boxers in Group 2: $216.6 \pm 30.6 \mathrm{~cm} / \mathrm{s}$ with their right hand, and $197.3 \pm 26.4 \mathrm{~cm} / \mathrm{s}$ with their left hand.

The indices of the maximal movement speed of boxers depend on the complexity of the task - quick and accurate movements were performed slower than simple and quick movements. Boxers in heavyweight categories demonstrated faster reaction, greater maximal hand movement speed and greater movement accuracy compared to lightweight category boxers, but the differences were not great.
\end{abstract}

Keywords: reaction time, movement speed, movement accuracy.

Gauta 2009 m. sausio 26 d.

Received on January 26, 2009

Priimta 2009 m. kovo $5 \mathrm{~d}$.

Accepted on March 5, 2009

Vidas Bružas

Lietuvos kūno kultūros akademija

(Lithuanian Academy of Physical Education)

Sporto g. 6, LT-44221 Kaunas

Lietuva (Lithuania)

Tel +370 37302664

E-mail v.bruzas@lkka.lt 